\title{
Multi-Market Collusion with Demand Linkages and Antitrust Enforcement
}

\author{
JAY PIL CHOI \\ HEIKO GERLACH
}

CESIFO WORKING PAPER NO. 2632

CATEGORY 11: INDUSTRIAL ORGANISATION

APRIL 2009

\footnotetext{
An electronic version of the paper may be downloaded

- from the SSRN website: www.SSRN.com

- from the RePEc website: $\quad$ www.RePEc.org

- from the CESifo website: www.CESifo-group.org/wp
} 


\title{
Multi-Market Collusion with Demand Linkages and Antitrust Enforcement
}

\begin{abstract}
This paper analyzes dynamic cartel formation and antitrust enforcement when firms operate in demand-related markets. We show that cartel prosecution can have a knock-on effect: desisting a cartel in one market reduces profits and cartel stability and leads to the break-up of the cartel in the adjacent market. Cartel prosecution can also have a waterbed effect: desisting a cartel increases cartel stability in the adjacent market and induces cartel formation in previously competitive markets. We also consider policy implications of our analysis regarding an antitrust authority's investment decision in cartel enforcement.
\end{abstract}

JEL Code: L13, L41, D43.

Keywords: cartel formation, demand linkage, antitrust enforcement.

Jay Pil Choi

Michigan State University

Department of Economics

USA - East Lansing, MI 48824

choijay@msu.edu
Heiko Gerlach

University of Auckland

Department of Economics

Private Bag 92019

New Zealand - Auckland

h.gerlach@auckland.ac.nz

April 2009

We would like to thank participants at various conferences and seminars for their comments. Gerlach acknowledges the support of the Barcelona GSE Research Network and the Government of Catalonia. 


\section{Introduction}

This paper analyzes the effect of demand linkages and antitrust enforcement on dynamic cartel formation when firms operate in several markets. A number of recent antitrust cases have highlighted the importance of demand relationships for multimarket cartels. In the aftermath of the Global Vitamins Cartel case, non-US buyers of bulk vitamins brought a class action to recover treble damages under US law for anticompetitive behavior occurring entirely outside of US commerce $]^{1}$ The foreign plaintiffs claimed that

"...the cartel raised prices around the world in order to keep prices in equilibrium with United States prices in order to avoid a system of arbitrage and therefore that the foreign plaintiffs were injured as a direct result of the increases in United States prices even though they bought vitamins abroad." (Empagran SA v. F. Hoffman-LaRoche, Ltd., 315F.3d 338, 431 (D.C. Cir. 2003))

In other words, it was suggested that in the presence of a negative demand linkage between different geographic markets a cartel in one market is necessary for sustaining the cartel in the other market. In 2004, the Supreme Court dismissed this argument and rejected the plaintiffs' claim.

Positive demand linkages arise when products are complements. The Vitamin D3 cartel, one of the 16 cartelized products during the Vitamin conspiracy, sold the majority of its production in an animal feed blend with Vitamin A known as "AD3". In 1992 Solvay Pharmaceuticals, a major producer of Vitamin D3, initiated contacts with Roche, producer of Vitamin A and D3 and at the time already involved in cartels in at least 11 product groups (including vitamin A). Roche, however, had no great desire to put up the price for D3 and stated

"its interest was to keep the D3 price premium in AD3 combinations low so as to boost its sales of the far more profitable vitamin $A$ in the AD3 compound." (European Commission Decision, 2003, para 459)

According to Roche, Solvay persisted and finally persuaded all D3 producers to meet and agree to a formal cartel scheme in early 1994. The Vitamin D3 cartel was the last

\footnotetext{
${ }^{1}$ Under an FTAIA exception to the Sherman Act foreign anticompetitive conduct falls under US jurisdiction if "such conduct has a direct, substantial and foreseeable effect" on US commerce.
} 
of all vitamin cartels to start and it ended before the big cartels, including Vitamin A which lasted until February 1999.2 Moreover, during its existence the vitamin D3 cartel had the lowest price increase and mark-up of all cartels ${ }^{3}$

In this paper we construct a model of multi-market contact with demand linkages and analyze the interplay of cartel formation and antitrust interventions. Consider an industry with two symmetric, demand-related markets and two firms active in both markets. Firms engage in repeated price competition over an infinite horizon and use trigger strategies that punish deviation in any market with infinite reversion to the perfectly competitive, static equilibrium of the stage game. Collusion leaves hard evidence that is detectable. In each market and period with an active cartel, the antitrust authority receives a cartel lead (say, from customers or disgruntled employees) with an exogenous probability. In our benchmark model the antitrust agency can prosecute a cartel in a given market only if it receives a cartel lead. Upon prosecution, the cartel is desisted, firms revert to competition in this market and an antitrust fine is imposed.

Our analysis shows that optimal dynamic cartel formation depends on whether a cartel in one market is easier to sustain if the adjacent market is cartelized or competitive. Two factors contribute to this relationship: the nature of the demand linkage and the effect of profits on cartel stability. If the demand linkage is negative (i.e. products are substitutes), then a cartel in the adjacent market increases demand and profits in the current market. If the demand linkage is positive (i.e. products are complements), it has the opposite effect. At the same time profits enter both discounted expected profits if the cartel persists in the next period and the gain from deviation. Cartel profits have a stronger effect on the former, and thereby a positive effect on cartel stability, if the discount factor is high and/or the detection probability is low. In contrast, if firms are less patient and/or detection and prosecution is more likely, then higher profits reduce cartel stability.

From this interaction we derive two important and intuitive effects of antitrust enforcement. First, we show that cartel prosecution in one market can have a knock-on effect on cartel activities in the adjacent market. If products are sufficiently close substitutes and the probability of cartel detection is low, then the desistance of one

\footnotetext{
${ }^{2}$ In August 1997 Roche, seemingly under the impression of the increased antitrust activities in the US, informed the other cartel members it would withdraw from their agreements although the parties continued their cartel arrangements until June 1998 (European Commission Decision, 2003, para 480, $628)$.

${ }^{3}$ The US price increase during the plea period for D3 was $19 \%$ compared to $61 \%$ for Vitamin A and $40 \%$ on average for all vitamins. It also had by far the lowest price mark-up of $15.6 \%$ compared to $48.8 \%$ for Vitamin A and 43.7 on average (Connor, 2007, chap 11, p. 275).
} 
cartel reduces profits and cartel stability in the adjacent market and triggers the internal break-up of the second cartel. Second, if firms operate in markets with a positive demand linkage, antitrust enforcement can have a waterbed effect. Successful prosecution of a cartel in one market increases cartel stability in the adjacent market and firms cartelize a previously competitive market. Such sequential cartels occur for two reasons. Collusion in both markets might not be sustainable whereas a cartel in one market at a time is feasible. Or, a sequential cartel yields higher expected profits compared to colluding in both market simultaneously.

We then extend this benchmark model and investigate the implications of these effects for the incentives of an antitrust authority (AA) to invest ex ante in prosecution resources. A higher prosecution budget allows the AA to conduct more comprehensive investigations. If one cartel is detected, the authority can (if necessary) extend its investigation and prosecute the cartel in the adjacent market. Firms anticipate these antitrust spillovers which has two effects. It induces firms to form sequential cartels more often and it deters the ex ante formation of cartels. We show that the optimal prosecution budget is a function of the level of available ex ante deterrence and the demand linkage. If deterrence is low, the authority invests if and only if products are neither close complements nor close substitutes. With strong complements firms form sequential cartels independent of prosecution resources and antitrust spillovers are not effective. If products are close substitutes, the AA benefits from the knock-on effect of cartel prosecution in one market. If deterrence is intermediate such that firms cartelize both markets if and only if the AA has a low prosecution budget, then investing in prosecution resources is optimal only if products are substitutes or weak complements.

Edwards (1955) first proposed the idea that the multiplicity of contacts among conglomerate firms may induce "mutual forbearance" and "blunt the edge of their competition". Bernheim and Whinston (1990) formalize this idea by showing that multi-market contact allows firms to pool the incentive constraints of the markets they operate in. Thereby, firms can transfer slack from more collusive markets to the markets where the incentive constraint is binding. In contrast, if firms and markets are identical, then multi-market contact does not strengthen firms' ability to collude $4^{4}$ We introduce both demand linkages and antitrust enforcement in the framework of Bernheim and Whinston (1990) and analyze the dynamic interplay of internal cartel stability and the AA's cartel prosecution strategy.

Our paper also relates to the literature on cartel antitrust enforcement. In particular, there is a small, but growing, literature on cartel pricing in the presence of an

\footnotetext{
${ }^{4}$ Spagnolo (1999) shows that the pro-collusive effect of multi-market contact is further strengthened if firms' profits enter a concave objective function.
} 
antitrust authority, and the effects of leniency programs on cartel stability. ${ }^{5}$ However, none of these papers deals with multi-market contact and demand linkages ${ }^{6}$ In a companion paper, Choi and Gerlach (2009), we analyze international antitrust enforcement when global firms operate cartels in markets within different antitrust jurisdictions. We demonstrate that demand linkages entail enforcement externalities across jurisdictions and a free-rider problem for local antitrust authorities. As a result, enforcement incentives may be non-linear in the degree of integration of the global economy.

The remainder of the paper is organized as follows. In section 2, we set up the basic model. Section 3 analyzes the benchmark case in which the antitrust authority has limited prosecution resources and only prosecutes cartels for which it receives cartel leads. Section 4 analyzes the AA's incentives to invest in prosecution resources. Section 5 discusses and concludes.

\section{The Model}

Consider two products $j=A, B$ and two firms, $i=1,2$ selling both products. The otherwise symmetric markets are linked through demand. Demand for good $j$ is defined by $D_{j}\left(\gamma ; p_{j}, p_{-j}\right) \equiv D\left(\gamma ; p_{j}, p_{-j}\right)$. Interchanging the prices of the two goods leads to an interchange of individual demand, and if the two products sell at the same price they have the same demand. The demand linkage is represented by the parameter $\gamma$ with $\gamma \in[\underline{\gamma}, \bar{\gamma}], \underline{\gamma}<0<\bar{\gamma}$, which measures the degree of substitutability and complementarity of the products. Assume the own price effect is negative and always dominates the cross price effect. The cross price effect is negative (positive) if $\gamma$ is negative (positive). Thus, if $\underline{\gamma} \leq \gamma<0$, the products are complements; if $0<\gamma<\bar{\gamma}$, the products are substitutes. The products are independent if $\gamma=0$. Further assume that the cross price effect increases (at equal prices) in $\gamma$, i.e. as this parameter increases, products become closer substitutes (or weaker complements). And, as $\gamma$ approaches $\underline{\gamma}$ $(\bar{\gamma})$, the products become perfect complements (substitutes).

The two firms are identical and produce with a constant marginal cost $c$. Define

\footnotetext{
${ }^{5}$ Harrington $(2004,2005)$ analyzes optimal cartel pricing when firms are concerned about creating suspicion and avoiding detection and prosecution. For recent work on leniency programs see Motta and Polo (2003), Aubert et al. (2006) and Harrington (2008).

${ }^{6}$ Roux and von Ungern-Sternberg (2007) analyze leniency programs in a multi-market setting without demand linkages to evaluate the DOJ's Amnesty Plus policy. They use a static model which precludes the analysis of cartel formation incentives. Nocke and White (2007) investigate cartel formation in vertically related industries. Their focus is on the effects of vertical mergers on upstream cartel formation and they do not consider antitrust enforcement of cartels.
} 
the maximum industry profit in one market given the other market is competitive as

$$
\Pi_{1}(\gamma) \equiv \max _{p}(p-c) D_{j}(\gamma ; p, c) .
$$

Further denote $\Pi_{2}(\gamma)$ as the per market industry profit if firms choose (symmetric) prices such that their profits over both markets are maximized,

$$
\Pi_{2}(\gamma) \equiv \frac{1}{2} \max _{p_{j}, p_{-j}}\left[\left(p_{j}-c\right) D_{j}\left(\gamma ; p_{j}, p_{-j}\right)+\left(p_{-j}-c\right) D_{-j}\left(\gamma ; p_{j}, p_{-j}\right)\right] .
$$

Suppose these reduced form profits are differentiable in $\gamma$ and make the following assumptions.

\section{Assumptions.}

$$
\begin{aligned}
& \Pi_{1}^{\prime}(\gamma)<0, \Pi_{1}^{\prime}(\gamma) \leq 2 \Pi_{2}^{\prime}(\gamma) \\
& \Pi_{1}(\underline{\gamma})=2 \Pi_{2}(\underline{\gamma}), \Pi_{1}(0)=\Pi_{2}(0), \Pi_{1}(\bar{\gamma})=0<\Pi_{2}(\bar{\gamma})
\end{aligned}
$$

Assumption (A1) states that industry profits per market strictly decrease in the demand linkage parameter when the adjacent market is competitive. The effect of $\gamma$ on profits with a competitive adjacent market is at least twice as strong as its effect on profits if the adjacent market is collusive 7 Assumption (A2) states that if products are perfect complements firms are able to extract total industry rents in one market independent of whether the other market is cartelized or not. If $\gamma=0$, per market profits are strictly positive and independent of the adjacent market. With perfect substitutes, industry profits are zero if one market is competitive and strictly positive if both markets are cartelized. Two more properties follow from these two sets of assumptions. Total industry profits across the two markets are weakly higher if firms cartelize both rather than one market. And it holds that $\Pi_{2}(\gamma) \geq(<) \Pi_{1}(\gamma)$ if and only if $\gamma \geq(<) 0$. If products are substitutes (complements), then the industry profit in one market is higher if the adjacent market is collusive (competitive).

The above assumptions hold across many commonly used demand structures. In particular, they apply to industries with differentiated products as well as to situations in which a homogenous product is sold in different geographic markets. We will use the following linear demand structure for differentiated goods, introduced by Singh \& Vives (1984), to illustrate some of our results.

Example 1 [Differentiated Products]. Assume two differentiated products and a unit mass of identical consumers with utility function

$$
U\left(x_{A}, x_{B}, H\right)=x_{A}+x_{B}-\frac{1}{2}\left(x_{A}^{2}+2 \gamma x_{A} x_{B}+x_{B}^{2}\right)+H
$$

\footnotetext{
${ }^{7}$ This condition ensures that the thresholds $F_{4}$ and $F_{4}^{S}$ in Lemma 3 and 5 , respectively, are upward sloping in $\gamma$. To ensure a unique intersection of the thresholds in our analysis, one could alternatively impose regularity conditions on the second derivatives of the profit functions.
} 
where $x_{j}$ is consumption of product $j, H$ is consumption of the Hicksian composite commodity and $\gamma, \gamma \in[-1,1]$, is the demand linkage parameter. Suppose both firms produce each of the two differentiated products. From the analysis in Singh 8 Vives (1984) follows $\Pi_{1}(\gamma)=(1-\gamma)(1-c)^{2} /[4(1+\gamma)]$ and $\Pi_{2}(\gamma)=(1-c)^{2} /[4(1+\gamma)]$.

Alternatively, for the case of substitutes, our formulation covers the case where a homogenous good is sold in two geographic markets and the cost of arbitrage determines the degree of the demand linkage.

Example 2 [Geographic Markets]. Assume two local markets with a demand of $D(p)$ for a homogenous good. The good is produced by two global firms who sell in both markets. Denote $p^{m}$ and $\Pi^{m}$ the local monopoly price and profits, respectively. Consumers have transportation (or arbitrage) cost of $t \geq 0$ per unit. They buy in their local market if the lowest local price is less or equal than the sum of the lowest price in the other market plus transportation cost. Define $\bar{\gamma} \equiv p^{m}-c$ and $\gamma \equiv \bar{\gamma}-t$. Then, for any $\gamma \in[0, \bar{\gamma}]$, it holds that $\Pi_{1}(\gamma)=(\bar{\gamma}-\gamma) D(c+\bar{\gamma}-\gamma)$ and $\Pi_{2}(\gamma)=\Pi^{m}$.

Firms are engaged in a repeated game in discrete time and maximize expected, discounted profits using a common discount factor of $\delta, 0 \leq \delta \leq 1$. In each period they decide whether to collude or compete in one or both markets. Deviations from the agreed prices are met with optimal punishment strategies, i.e. the perfect equilibrium providing the lowest profits (Abreu, 1988). In our context any deviation is punished with eternal reversion to competition in both markets, thus, firms repeat the static Bertrand solution and receive discounted profits of zero in both markets.

Collusion in a market leaves hard evidence and the possibility of antitrust enforcement by the antitrust authority (AA, henceforth). There are three enforcement stages in the prosecution of cartels. First, price-fixing conspiracies need to be discovered. Second, discovered conspiracy schemes need to be prosecuted. Finally, successfully prosecuted cases need to be penalized to break up the existing cartels and deter the formation of future cartels. As pointed out by Harrington (2006), the role of the antitrust authorities in the discovery stage has been minimal in that they are typically a passive agent that responds to complaints by disgruntled employees and suspicious customers who provide initial leads on price-fixing schemes. To reflect this reality, we assume that if a cartel exists, the AA receives information about the cartel with an exogenous probability of $\rho(\geq 0)$, in each period ${ }^{8}$ This probability of detection is independent across markets and over time ${ }^{9}$ The information provided to the AA

\footnotetext{
${ }^{8}$ Bryant and Eckart (1991) use a large sample of DOJ cases and find that the probability that a price-fixing conspiracy will be indicted in a given year is at most between 0.13 and 0.17.

${ }^{9}$ We introduce the possibility of antitrust spillovers across markets in Section 4.
} 
is hard evidence and the basis of the AA's use of its investigative powers in the second phase. The final stage is captured by the following two implications for firms. First, the antitrust authority imposes the maximal stipulated fine $F>0$ on each cartel member ${ }^{10}$ Moreover, a successful prosecution imposes antitrust compliance of firms in the cartelized market. This assumption captures the idea that after an investigation firms remain to some extent "under the radar" of the AA. Either indirectly because the AA has obtained useful market information during the investigation which allows light monitoring. Or directly in case the AA requires firms to produce reports on their market strategy. In fact, Kovacic et al. (2006) analyze the pricing of the Vitamin cartel members after their conviction and show that all except two of the Vitamin markets displayed a downward adjustment of prices during 12 to 36 months before arriving at a new price level that seemed to correspond to a new more competitive equilibrium 11 For simplicity, we assume that, once convicted, firms never engage in collusion in the same market again $\sqrt[12]{2}$ Finally, we impose a parameter restriction on the discount factor and the detection probability which is a necessary condition for collusion to be sustainable in the model.

\section{Assumption.}

$$
\delta(1-\rho) \geq 1 / 2 .
$$

Note that this constraint requires $\delta \geq 1 / 2$ and $\rho \leq 1 / 2$.

To summarize, the timing of the repeated stage game is as follows. Firms decide whether to collude in one market, both markets or not at all as a function of the prosecution history. Firms set their prices and receive their profits. At the end of the period the AA discovers and prosecutes a cartel with probability $\rho$. Upon prosecution firms pay the fine and stop fixing prices in the market. In the next section we analyze the subgame perfect equilibrium of this game.

\section{Equilibrium Analysis}

In this section we consider an exogenous antitrust enforcement regime. In each period a cartel is detected and successfully prosecuted with probability $\rho$. Upon prosecution

\footnotetext{
${ }^{10}$ For example, the European Commission can impose a maximum amount of $10 \%$ of the company's total revenues in the year preceding the decision. In the U.S. the maximum fine for a company is the greatest of $\$ 100$ million, twice the gross gain to the cartel or twice the gross harm of the cartel.

${ }^{11}$ Only the carotinoids took a full three years after the last formal cartel meeting before prices started to go down.

${ }^{12}$ The qualitative nature of our results does not change if this desistance effect is only temporary, say for $T$ periods.
} 
firms pay a fine and cease to collude in this market forever. This means that firms are in one of three states: (i) no cartel has been prosecuted, (ii) a cartel has been prosecuted in exactly one market, and (iii) a cartel in both markets has been convicted (in which case firms receive a continuation value of zero). In the following we first analyze the sustainability of collusion in the first two cases and then consider firms' optimal cartel organization.

Sustainability of collusion in one market. Suppose that a cartel in exactly one market has been desisted and firms return to competition in this market. Then, the profits from collusion in the adjacent market are recursively defined as

$$
V_{1}^{C}=\Pi_{1}(\gamma) / 2-\rho F+(1-\rho) \delta V_{1}^{C}
$$

In the current period firms equally share profits in this market. The cartel is successfully prosecuted with probability $\rho$ in which case firms pay a fine of $F$ and receive competitive profits from the next period onwards. If the cartel is not detected, firms continue to collude in the next period. This cartel is sustainable if collusion profits exceed the value from a one-off price deviation and eternal reversion to the competitive equilibrium. Thus it has to hold that

$$
V_{1}^{C}=\frac{\Pi_{1}(\gamma) / 2-\rho F}{1-\delta(1-\rho)} \geq \Pi_{1}(\gamma)
$$

or

$$
(\delta(1-\rho)-1 / 2) \Pi_{1}(\gamma) \geq \rho F
$$

The LHS of (1) is by Assumption (A3) always positive. The cartel is internally stable if the expected, discounted future collusion profits outweigh the current gains from deviation and the expected cartel fine. A tougher antitrust enforcement reduces the value of collusion whereas higher industry profits stabilize the cartel. Note that the latter implies that partial collusion is never optimal. Firms collude at the industry profit maximizing price or there is no cartel at all. Define $F_{1}$ as the value of $F$ that satisfies condition (1) with equality and let $V_{1}$ be the value function of a representative firm in one market when the other market is competitive,

$$
V_{1}= \begin{cases}V_{1}^{C} & \text { if } F \leq F_{1} \\ 0 & \text { otherwise }\end{cases}
$$

Sustainability of collusion in both markets. Now consider the situation in which no cartel has been prosecuted in either market. Suppose firms collude in both markets simultaneously. In the current period a firm receives half of each market's 
industry profit. If no cartel is detected, collusion persists in both markets. If one cartel is detected, firms pay the antitrust fine and get the expected value from collusion in the adjacent market. If both cartels are detected, firms are fined and collusion stops thereafter. The present discounted value of a firm, $V_{2}$, is recursively given by

$$
V_{2}=\Pi_{2}(\gamma)+\delta(1-\rho)^{2} V_{2}+2 \rho(1-\rho)\left(\delta V_{1}-F\right)-2 \rho^{2} F,
$$

which gives

$$
V_{2}=\frac{\Pi_{2}(\gamma)+2 \rho(1-\rho) \delta V_{1}-2 \rho F}{1-\delta(1-\rho)^{2}} .
$$

Deviations are punished with Nash reversion in both markets. Thus, firms optimally deviate (and shave the cartel price) in both markets and collusion is sustainable if and only if $V_{2} \geq 2 \Pi_{2}(\gamma)$ or, equivalently,

$$
\delta(1-\rho)^{2} \Pi_{2}(\gamma)+\delta \rho(1-\rho) V_{1} \geq \Pi_{2}(\gamma) / 2+\rho F .
$$

This condition gives the per market incentive constraint for sustaining collusion. The first term on the LHS is the expected future cartel profit if no cartel is discovered. The second term is the expected continuation profit if the cartel in the adjacent market is discovered in the current period. These profits have to outweigh the market share gain from deviation and the expected cost of antitrust enforcement.

Two cases have to be distinguished. First, suppose collusion in one market would still be viable if the cartel in the other market is desisted, that is, condition (1) holds and $V_{1}=V_{1}^{C}$. Then (2) can be written as

$$
V_{1}^{C}-\Pi_{1}(\gamma)+\left[\delta(1-\rho)^{2}-1 / 2\right] \frac{\Pi_{2}(\gamma)-\Pi_{1}(\gamma)}{1-\delta(1-\rho)^{2}} \geq 0 .
$$

The net value from collusion in both markets, i.e. cartel profits minus deviation profits, is decomposed in two parts. The first term, $V_{1}^{C}-\Pi_{1}(\gamma)$, is the cartel net value if the adjacent market is competitive. From condition (1) follows that this expression is decreasing in $F$, positive for $F<F_{1}$ and zero if $F=F_{1}$. The second term is the added value from a cartel in the adjacent market. In each period of the expected, discounted survival time of both cartels, total cartel profits increase or decrease by $\Pi_{2}(\gamma)-\Pi_{1}(\gamma)$. This profit difference enters both future expected cartel profits and the gains from deviation in the current period. It raises discounted future profits by the probability that no cartel is discovered in the current period. At the same time deviation profits increase by the $50 \%$ market share gain from deviation. The overall net effect on cartel stability depends on the sign of the term in brackets. If the bracketed term is positive (negative), then higher per period profits from a cartel in the adjacent market raise (reduce) overall cartel stability. 
From this follows that if a single-market cartel is viable, then collusion in both markets is always sustainable if the second term in (3) is positive. This holds if either products are substitutes and the cartel stability factor is positive or if products are complements and $\delta(1-\rho)^{2}<1 / 2$. On the other hand, if condition (1) is sufficiently tight and the second term in (3) is negative, then multi-market collusion is harder to sustain than single-market collusion. This can occur in two cases. First, it holds if products are complements and $\delta(1-\rho)^{2}>1 / 2$. In this case cartel stability increases in cartel profits. This implies that if full collusion is not sustainable, then partial collusion (with lower prices and profits) is not feasible either. And secondly, it holds if products are substitutes and $\delta(1-\rho)^{2}<1 / 2$. In this case the sustainability of multi-market collusion increases if firms reduce prices and profits in both markets. Thus, although full collusion is not sustainable, firms are able to implement partial collusion and supracompetitive profits in both market. Denote as $F_{2}$ the value of $F$ such that condition (3) holds if and only if $F \leq F_{2}$. The following lemma formalizes this discussion.

Lemma 1 Suppose condition (1) holds, i.e. collusion in one market is sustainable when the adjacent market is competitive.

(i) If $\delta(1-\rho)^{2} \geq 1 / 2$ and products are complements, then there exist values $0<F_{2} \leq$ $F \leq F_{1}$ such that collusion in both markets simultaneously is not sustainable.

(ii) If $\delta(1-\rho)^{2}<1 / 2$ and products are substitutes, then there exist values $\max \left\{0, F_{2}\right\} \leq$ $F \leq F_{1}$ such that firms can only sustain partial collusion in a simultaneous cartel.

(iii) Otherwise, firms can always sustain a simultaneous cartel.

Now suppose condition (1) does not hold and collusion in one market would not be viable if the adjacent market is competitive, i.e. $V_{1}=0$. Then the per market incentive constraint for sustaining both cartels is

$$
\left[\delta(1-\rho)^{2}-1 / 2\right] \Pi_{2}(\gamma) \geq \rho F
$$

Firms have to sustain collusion with the cartel net value generated during the phase in which none of the two cartels is discovered. This makes a positive cartel stability factor, $\delta(1-\rho)^{2}>1 / 2$, a necessary condition for successful collusion. Now compare the single-market and multi-market incentive constraints. The differences between (1) and (4) are due to the demand linkage between markets and antitrust enforcement. Cartelizing the adjacent market has a positive (negative) effect on per market profits if products are substitutes (complements). At the same time antitrust enforcement and reversion to competition is more likely if firms cartelize both markets. Thus, if products are complements, independent or weak substitutes, then multi-market collusion is not sustainable if single-market collusion is not feasible. By contrast, if products 
are sufficiently close substitutes, then the positive profit effect outweighs the higher antitrust risk and firms are able to sustain collusion in both markets although singlemarket collusion is not feasible. This is formalized in the following lemma. Denote as $F_{3}$ the maximum value of $F$ for which (4) holds.

Lemma 2 Suppose condition (1) does not hold, i.e. collusion in one market is not sustainable if the adjacent market is competitive. If $\delta(1-\rho)^{2}>1 / 2$ and $\gamma \geq \gamma_{1}$, with $\gamma_{1}>0$, then there exist parameter values $F_{1} \leq F \leq F_{3}$ such that firms can sustain collusion in both markets simultaneously. Otherwise, collusion is not sustainable.

Optimal Organization of Collusion. Collusion in both markets simultaneously is not always possible and may not always be the profit-maximizing organization of collusion. Consider sequential cartels instead. Firms cartelize one market and price competitively in the adjacent market. Once the cartel has been discovered and desisted, they start collusion in the second market. Such sequential collusion yields a present discounted, expected value of

$$
V_{11}=V_{1}^{C}+\frac{\delta \rho}{1-\delta(1-\rho)} V_{1}^{C} .
$$

This sequential cartel organization is sustainable if and only if condition (1) holds. To see this note that the first cartel is always easier to sustain than the second because a deviating firm loses the discounted value of both streams of collusive profits. Thus, as long as the constraint for the second cartel, (1), holds, firms can sustain both cartels. If (1) does not hold, then the first cartel faces the same incentive constraint as the second cartel and is therefore not viable.

Now suppose both simultaneous and sequential cartels are internally stable, i.e. $F \leq$ $\min \left\{F_{1}, F_{2}\right\}$. What are the strategic incentives for a sequential cartel? Simultaneously cartelizing both markets dominates sequential cartels if and only if $V_{2} \geq V_{11}$, or,

$$
\frac{1-\delta}{1-\delta(1-\rho)} V_{1}^{C}+\frac{\Pi_{2}(\gamma)-\Pi_{1}(\gamma)}{1-\delta(1-\rho)^{2}} \geq 0
$$

From an ex ante point of view, firms cartelize each market for the same expected time under both types of collusion. In a simultaneous cartel firms collude in two markets from the beginning whereas in a sequential cartel the second market is cartelized later. The first term in (5) is the expected, discounted profit advantage of a simultaneous cartel from having the second cartel earlier. This expression is always positive. The second term is the expected, discounted profit difference per market as long as both cartels remain undetected in the simultaneous collusion scheme. If the products are substitutes, then $\Pi_{2}(\gamma)>\Pi_{1}(\gamma)$ and a simultaneous cartel allows firms to implement 
a higher per market profit in this phase. If the products are complements, a sequential cartel yields higher profits per market. From this follows that if products are substitutes or independent, then both terms in (5) are weakly positive and it is always optimal for firms to collude simultaneously in both markets. If products are complements, then firms have to trade off the higher per period profits in a sequential cartel with the later start of the cartel in the adjacent market. The advantage of a sequential cartel is bigger, the stronger the complementarity between the markets. The advantage of having the second cartel earlier in a simultaneous cartel decreases with the antitrust fine $F$. Hence, there exists a threshold value $F_{4}$ such that for $F \geq F_{4}$, firms prefer sequential collusion. Moreover, note that the more patient firms are, the smaller the advantage of a simultaneous cartel. In particular, if $\delta=1$, then the arrival time of the second cartel is irrelevant and a simultaneous (sequential) cartel dominates if products are substitutes (complements). We formalize this discussion as follows.

Lemma 3 Suppose simultaneous and sequential cartels are sustainable.

(i) If products are substitutes, firms always prefer to form a simultaneous cartel.

(ii) If products are complements and $F \geq F_{4}$, then firms prefer a sequential cartel.

(iii) It holds that $\partial F_{4} / \partial \gamma \geq 0$ and there exist $\gamma_{2}$ and $\gamma_{3}$, with $\underline{\gamma}<\gamma_{2} \leq \gamma_{3} \leq 0$ such that $F_{4} \geq 0$ iff $\gamma \geq \gamma_{2}$, and $F_{4} \leq \min \left\{F_{1}, F_{2}\right\}$ iff $\gamma \leq \gamma_{3}$.

We are now in a position to characterize optimal dynamic cartel formation. In the following proposition we focus on the case where the stability of a simultaneous cartel increases in its profits. We comment on the case where $\delta(1-\rho)^{2} \leq 1 / 2$ in the discussion below.

Proposition 1 Assume $\delta(1-\rho)^{2} \geq 1 / 2$ and consider optimal cartel formation.

(i) If $F \leq \min \left\{F_{1}, F_{2}, F_{4}\right\}$, then firms cartelize both markets and continue collusion in the adjacent market if one cartel is desisted.

(ii) If products are complements and $\min \left\{F_{2}, F_{4}\right\}<F \leq F_{1}$, then firms cartelize one market and start collusion in the adjacent market if this cartel is desisted.

(iii) If products are substitutes and $F_{1}<F \leq F_{3}$, then firms cartelize both markets and stop collusion in both markets if one cartel is desisted.

(iv) If $F \geq \max \left\{F_{1}, F_{3}\right\}$, there is no collusion.

Proposition 1 identifies four parameter regimes with different cartel dynamics and antitrust interventions. FIGURE 1 illustrates the regimes corresponding to Proposition 1 in a $(F, \gamma)$-diagram using the profit functions derived from Example 1 in Section 2. 


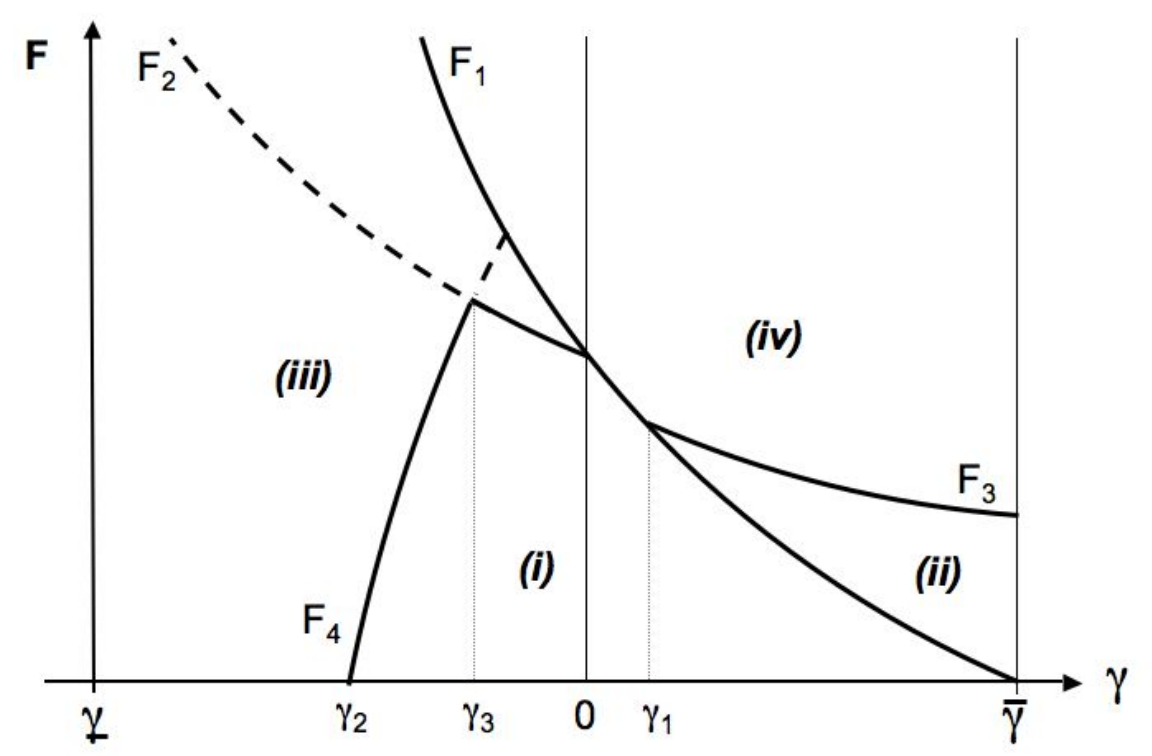

Figure 1: Optimal Cartel Formation for $\delta(1-\rho)^{2} \geq 1 / 2$.

In regions (i) cartel deterrence is low and markets are neither strong substitutes nor strong complements. Here firms collude in both markets until the AA has successfully prosecuted both cartels. In particular, if the AA detects and desists one cartel, the cartel in the adjacent market remains active. In region (ii) firms start colluding in both markets simultaneously. However, in this regime antitrust prosecution has a knock-on effect due to the negative demand linkage. If exactly one of the two cartels is discovered, firms disrupt their cartel activity in the prosecuted market and the price returns to the competitive level. Since products are substitutes, demand and profits in the adjacent market decrease and erode cartel stability in the non-prosecuted market. Hence in this regime, one antitrust intervention is sufficient to eliminate collusion in both markets. A necessary condition for this knock-on effect to exist is that antitrust fines are neither too low nor too high. If they are low, firms continue to collude in the adjacent market. If they are high, all cartel activities are deterred. In region (iii) firms form sequential cartels for two reasons. First, a sequential cartel dominates cartelizing both markets while both types of cartels are viable. This occurs if products are sufficiently strong complements. And second, a sequential cartel is chosen because a simultaneous cartel is not viable. This happens if antitrust fines (and deterrence) are intermediate, i.e. $F_{2}<F \leq F_{1}$. In both cases, firms collude until the AA has successfully prosecuted a cartel in each market, but unlike in region (i), here, the AA always has to desist the cartels one by one. Finally, in region (iv) antitrust deterrence is sufficiently high to prevent cartel formation ex ante.

To conclude this section, let us briefly comment on the case where the stability of a simultaneous cartel decreases in the cartel's current period profits, i.e. $\delta(1-\rho)^{2}<1 / 2$. 
It follows straight from Lemma 2 that if $F>F_{1}$, then collusion is never feasible. Consider the case where a cartel in one market is sustainable while the adjacent market is competitive, $F \leq F_{1}$. From Lemma 1 it follows that if products are complements, then a simultaneous cartel is always sustainable. However, it is dominated by a sequential cartel if and only if $F \geq F_{4}$. If products are substitutes, firms resort to partial collusion in both markets if $\max \left\{0, F_{2}\right\} \leq F \leq F_{1}$; otherwise, they are able to implement full collusion in both markets. Note that partial collusion always dominates a sequential cartel organization for these parameter values. To see this verify from (3) that at $F=F_{1}$, where $V_{1}^{C}=\Pi_{1}(\gamma)$, firms are able to sustain a per market profit of $\Pi_{1}(\gamma)$. For any lower value of $F$ firms can sustain higher profits. Since the profit stream with partial collusion has to match simultaneous deviation in both markets, a partially colluding cartel has an expected value of at least $2 \Pi_{1}(\gamma)$, which strictly dominates what a sequential cartel can achieve.

\section{Optimal Cartel Prosecution}

In this section we extend the analysis and explore the incentives of an Antitrust Authority (AA) to invest in cartel prosecution resources in our framework. We posit that the intensity of cartel prosecution is limited by the resources that the AA devotes to it 13 In particular, we suppose that an AA with a low cartel prosecution budget acts as a passive agent who can only follow up on cartel leads it receives from the industry. A well-funded cartel prosecution unit, by contrast, is able to use an initial cartel lead in one market and extend, if necessary, the investigation into adjacent markets.

Consider the following simple extension of the model. As before, we assume that a cartel is discovered with an exogenous probability $\rho$ and produces hard evidence that the AA can use to successfully prosecute the cartel. To start an investigation the AA needs at least one cartel lead. Suppose that in each period the AA has sufficient resources to follow up and successfully prosecute all cartels for which it receives cartel leads. Alternatively, the AA can adopt a pro-active stance by investing ex ante in its cartel prosecution resources. The investment cost is $I \geq 0$. This is the cost of increasing the overall budget of the AA and/or the opportunity cost of shifting resources from

\footnotetext{
${ }^{13}$ Connor (2007), for example, argues that after the successful reforms of antitrust laws in the last two decades, the main current impediment to antitrust enforcement is the serious under-funding of competition authorities around the world. In the US an increase in merger activities and high-profile cases such as Microsoft have absorbed large proportions of the DOJ resources and "... the Division's employees are in danger of being overworked or potential antitrust violations going uninvestigated." (Connor 2007, p. 421)
} 
other policy areas, like mergers or state aids into cartel prosecution. The investment allows the AA to open - when required - more comprehensive investigations. In particular, in our context, if the AA receives a cartel lead in exactly one market, the AA is able to extend the investigation into the adjacent market and successfully prosecute the second cartel.14

The AA minimizes the sum of the expected loss of consumer surplus due to cartel activities and its enforcement cost. Denote $S_{2}(\gamma), S_{1}(\gamma)$ and $S_{0}(\gamma)$ as the per period consumer surplus in both markets if there is collusion in both markets, collusion in one market only, and no collusion, respectively. Then the per period loss of consumer surplus due to a cartel in one market is defined as $L_{1}(\gamma)=S_{0}(\gamma)-S_{1}(\gamma)$. Similarly, the consumer welfare (across the two markets) if both markets are cartelized is $L_{2}(\gamma)=$ $S_{0}(\gamma)-S_{2}(\gamma)$. We make the following assumptions on these functions and the model parameters.

\section{Assumptions.}

$$
\begin{aligned}
& L_{1}^{\prime}<0, L_{1}^{\prime} \leq L_{2}^{\prime} \\
& L_{1}(\underline{\gamma})=L_{2}(\underline{\gamma}), 2 L_{1}(0)=L_{2}(0), L_{1}(\bar{\gamma})=0<L_{2}(\bar{\gamma}) \\
& \delta(1-\rho)^{2} \geq 1 / 2
\end{aligned}
$$

Consumer loss from a cartel with a competitive adjacent market is strictly decreasing in the substitutability (or increasing in the complementarity) of the markets. If both markets are cartelized, then consumer loss might increases or decrease in $\gamma$ but its slope is always weakly higher compared to the loss with a competitive adjacent market. If products are perfect complements, then a cartel in one market is able to fully extract the cartel surplus from the adjacent market. If markets are independent, two cartels create double the harm of one cartel. If products are perfect substitutes, then one cartelized market is not causing any loss in consumer surplus whereas consumers are strictly harmed if both markets are cartelized. Further it follows from (A4) and (A5) that the welfare loss with two active cartels is at least as high as with one cartel and that $L_{2}(\gamma)-L_{1}(\gamma)>(<) L_{1}(\gamma)$ if and only if the markets are substitutes (complements). The latter means that if products are substitutes (complements), then desisting a cartel is more desirable if the adjacent market is collusive (competitive). Finally, by assumption (A6), we focus in this section on the parameter case where a simultaneous cartel becomes more stable if its per period profits increase.

In the following we derive optimal cartel formation if the AA operates with a large prosecution budget and firms expect antitrust spillovers. Then, we compare with the

\footnotetext{
${ }^{14}$ In equilibrium, the AA knows when it is optimal for firms to form simultaneous cartels and investigations in the adjacent market only occur when there is a cartel to be prosecuted.
} 
outcome in the benchmark model. Finally, we analyze the AA's incentives to invest in its prosecution resources.

Cartel Formation with Antitrust Spillovers. Suppose the AA has invested in its prosecution budget. If the AA receives two cartel leads it prosecutes both cartels. If it receives one cartel lead, it investigates and prosecutes the cartel in the adjacent market, too. Firms anticipate that if they are caught in at least one market, both cartels are prosecuted. Thus, the expected value from colluding in both market, $V_{2}^{S}$, is implicitly defined by

$$
V_{2}^{S}=\Pi_{2}(\gamma)+\delta(1-\rho)^{2} V_{2}^{S}-\rho(2-\rho) 2 F
$$

which gives

$$
V_{2}^{S}=\frac{\Pi_{2}(\gamma)-\rho(2-\rho) 2 F}{1-\delta(1-\rho)^{2}}
$$

This discounted, expected profit with antitrust spillovers is less than what firms achieve in a simultaneous cartel in the benchmark model. Consequently, a simultaneous cartel is harder to sustain and more likely to be dominated by a sequential cartel. To see this consider in turn the cartel stability condition and the condition under which a simultaneous cartel dominates a sequential cartel. Collusion with antitrust spillovers is sustainable if $V_{2}^{S} \geq 2 \Pi_{2}$ or

$$
\left[\delta(1-\rho)^{2}-1 / 2\right] \Pi_{2}(\gamma) \geq \rho(2-\rho) F
$$

Denote $F_{3}^{S}$ the threshold value such that for all $F \leq F_{3}^{S}$ a simultaneous cartel is viable. The only difference to the cartel stability condition in the benchmark model is that with antitrust spillovers, the cartel's net value has to overcome a higher expected cost from antitrust enforcement. Hence, it has to hold that $F_{3}^{S}<F_{3}$. Now consider sequential cartels. If firms form one cartel at a time, antitrust spillovers are not effective and sequential cartels are viable if and only if $F \leq F_{1}$. Compare the sustainability of a sequential and a simultaneous cartel.

Lemma 4 There exists a $\gamma_{1}^{S}>\gamma_{1}>0$ such that the following holds.

(i) If $\gamma \geq \gamma_{1}^{S}$, then there exist values $F_{1} \leq F \leq F_{3}^{S}$ such that a simultaneous cartel is sustainable while a sequential cartel is not.

(ii) If $\gamma \leq \gamma_{1}^{S}$, then there exist values $F_{3}^{S} \leq F \leq F_{1}$ such that a sequential cartel is sustainable while a simultaneous cartel is not.

(iii) If $F \leq \min \left\{F_{1}, F_{3}^{S}\right\}$, then both forms of cartel organization are sustainable.

(iv) Otherwise, collusion is deterred. 
In the benchmark model a simultaneous (sequential) cartel is easier to sustain if markets are substitutes (complements). With antitrust spillover a simultaneous (sequential) cartel is easier to sustain if products are sufficiently close substitutes (complements or weak substitutes). Suppose that both simultaneous and sequential cartels are sustainable. A simultaneous cartel dominates a sequential cartel if and only if $V_{2}^{S} \geq V_{11}$ or

$$
\frac{1-\delta}{1-\delta(1-\rho)} V_{1}^{C}+\frac{\Pi_{2}(\gamma)-\Pi_{1}(\gamma)}{1-\delta(1-\rho)^{2}}-\frac{2 \rho(1-\rho)\left(\delta V_{1}^{C}+F\right)}{1-\delta(1-\rho)^{2}} \geq 0
$$

The first two terms are the same as in (5) in the benchmark model. The third term is the additional, relative cost of a simultaneous cartel due to the antitrust spillover. If exactly one cartel is detected, firms lose the profit stream of the cartel in the adjacent market and they pay the fine. This loss is discounted by the expected arrival time of an antitrust spillover. Define $F_{4}^{S}$ as the value of $F$ such that (7) holds with equality. Consider the properties of this threshold and compare it with the threshold values for cartel sustainability.

Lemma 5 Suppose simultaneous and sequential cartels are sustainable. If $F \geq F_{4}^{S}$, then firms prefer to form a sequential cartel. It holds that $F_{4}^{S}<F_{4} . F_{4}^{S}$ increases in $\gamma$ and there exist $\gamma_{2}^{S}$ and $\gamma_{3}^{S}$, with $\gamma_{2}<\gamma_{2}^{S} \leq \gamma_{3}^{S}<\gamma_{1}^{S}$, such that $F_{4}^{S} \geq 0$ iff $\gamma \geq \gamma_{2}^{S}$, and $F_{4} \leq \min \left\{F_{1}, F_{3}^{S}\right\}$ iff $\gamma \leq \gamma_{3}^{S}$.

The fact that $\gamma_{3}^{S}<\gamma_{1}^{S}$ establishes that - like in the benchmark model - sequential cartels might form for two reasons. First, a sequential cartel dominates the simultaneous cartel while both are feasible. This occurs for $F \leq \min \left\{F_{1}, F_{3}^{S}\right\}$ and $F \geq F_{4}^{S}$. Second, a sequential cartel forms because a simultaneous cartel is deterred which holds for $F_{3}^{S} \leq F \leq F_{1}$.

Proposition 2 Consider optimal cartel formation with antitrust spillovers.

(i) If $F \leq \min \left\{F_{3}^{S}, F_{4}^{S}\right\}$, then firms cartelize both markets.

(ii) If $\min \left\{F_{3}^{S}, F_{4}^{S}\right\}<F \leq F_{1}$, then firms cartelize one market and start collusion in the adjacent market if the cartel has been desisted.

(iii) Otherwise, there is no collusion.

Before analyzing the optimal prosecution strategy, it is useful to compare cartel formation without antitrust spillovers to the results of Proposition 2. As discussed above, cartel spillovers reduce the profitability of a simultaneous cartel. This has two effects. First, it increases firms' incentives to form sequential cartel which are unaffected by spillovers. Second, if sequential cartels are not sustainable, then the threat of antitrust spillovers can deter the ex ante formation of cartels. This is illustrated in FigurE 2 which plots the threshold values in a $F$ - $\gamma$ diagram using Example 1 from Section 2. 


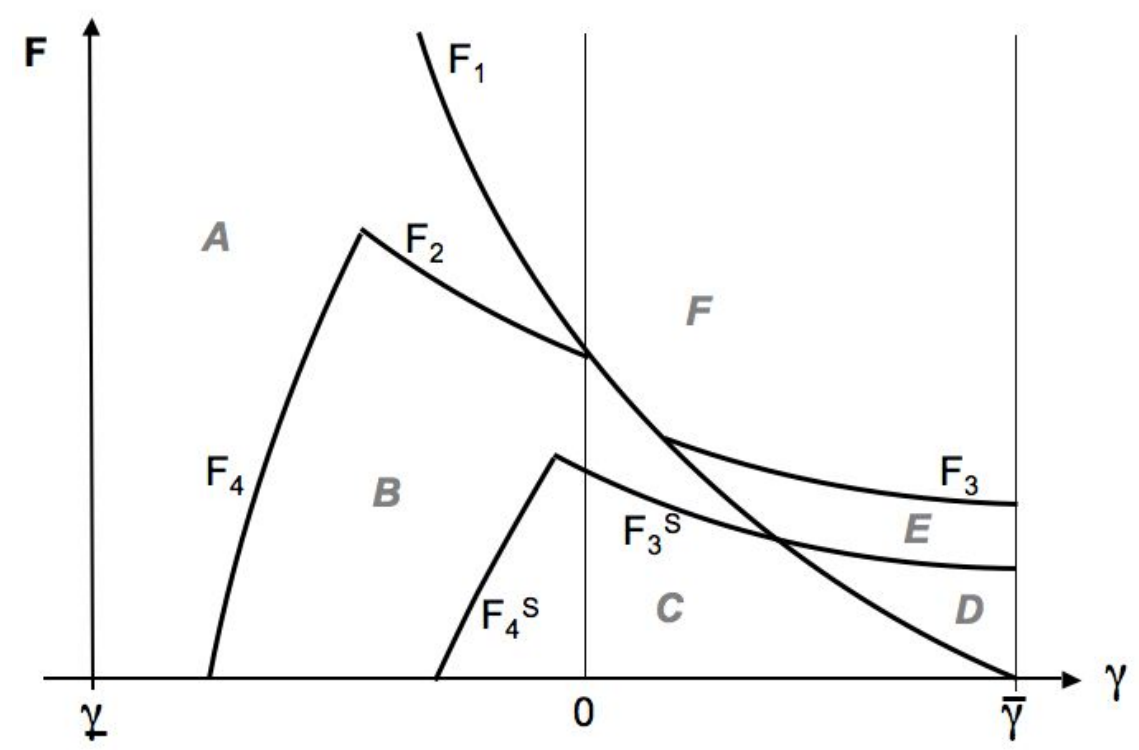

Figure 2: Optimal Cartel Formation with and without antitrust spillovers..

Sequential cartels are viable if and only if $F \leq F_{1}$. In regions $\mathrm{A}$ and $\mathrm{C}$ optimal cartel organization is independent of the AA's prosecution strategy. In region A firms form sequential cartels; in region $\mathrm{C}$ they always form simultaneous cartels. By contrast, in region $\mathrm{B}$ firms choose a simultaneous cartel if the AA uses a low budget prosecution strategy while they form a sequential cartel in the presence of antitrust spillovers. In region $\mathrm{D}, \mathrm{E}$ and $\mathrm{F}$ sequential cartels are not sustainable. In region $\mathrm{D}$ firms cartelize both markets but after at least one cartel is detected and prosecuted, both markets become competitive. In region E prosecution resources affect the level of deterrence. A low prosecution budget leads to a simultaneous cartel that breaks down if at least one cartel is desisted whereas the possibility of antitrust spillovers deters cartel formation. In region $\mathrm{F}$, cartel formation is deterred independent of the prosecution strategy.

Optimal Cartel Prosecution. We now investigate under which conditions the AA has an incentive to invest in prosecution resources. In region A firms form sequential cartels independent of the prosecution strategy. Since antitrust spillovers are ineffective with sequential cartels, there is no gain for the AA from investing in prosecution resources. In region $\mathrm{B}$, prosecution resources affect the optimal organization of the cartel. If the AA does not invest, firms form a simultaneous cartel. The ex ante discounted and expected consumer welfare loss from a simultaneous cartel without antitrust spillover, $W_{2}$, is recursively defined as

$$
W_{2}=L_{2}(\gamma)+2 \rho(1-\rho) \delta W_{1}^{C}+(1-\rho)^{2} \delta W_{2}
$$

where

$$
W_{1}^{C}=\frac{L_{1}(\gamma)}{1-\delta(1-\rho)}
$$


is the discounted and expected welfare loss from a cartel in one market while the adjacent market is competitive. Solving yields

$$
W_{2}=\frac{2 L_{1}(\gamma)}{1-\delta(1-\rho)}+\frac{L_{2}(\gamma)-2 L_{1}(\gamma)}{1-\delta(1-\rho)^{2}}
$$

The first term is the expected loss from cartels in both markets while the adjacent market is competitive. The second term is the profit adjustment due to the demand linkage during the phase in which both markets are cartelized. This expression is positive if products are substitutes and negative if they are complements. Now suppose the AA increases its prosecution budget and firms form a sequential cartel. The discounted, expected welfare loss from a sequential cartel is

$$
W_{11}=\left[1+\frac{\rho \delta}{1-\delta(1-\rho)}\right] \frac{L_{1}(\gamma)}{1-\delta(1-\rho)},
$$

which is the sum of the two single-market cartels where the second cartel is discounted by its later expected starting date. Investing in prosecution resources is optimal if the welfare gain from facing a sequential rather than a simultaneous cartel outweighs the cost, $W_{2}-W_{11} \geq I$, or

$$
\frac{(1-\delta) L_{1}(\gamma)}{(1-\delta(1-\rho))^{2}}+\frac{L_{2}(\gamma)-2 L_{1}(\gamma)}{1-\delta(1-\rho)^{2}} \geq I
$$

The first term is the difference in expected, discounted harm due to the fact that in a sequential cartel one market is cartelized later. If the AA does not discount future losses, this expression is zero. The second term is the effect of the demand linkage in a simultaneous cartel while both markets are cartelized. It is positive if products are substitutes and negative with complements. Overall, the welfare gain from a sequential cartel, i.e. the LHS of (8), is strictly positive for substitutes and weak complements. With perfect complements, the per period welfare loss is independent of how many markets are cartelized and a simultaneous cartel is strictly superior - from the AA's perspective - because of its lower expected, discounted duration. Furthermore, it can be shown that, by assumption (A4), the welfare gain from a sequential cartel, increases in the demand linkage parameter. Hence, the AA invests in cartel prosecution if $\gamma$ is sufficiently large.

Lemma 6 Consider parameter region B. There exists a $\gamma_{B}(I)$, with $\gamma_{B}^{\prime}>0$ and $\underline{\gamma}<$ $\gamma_{B}(0)<0$, such that the $A A$ invests in prosecution resources if and only if $\gamma \geq \gamma_{B}(I)$.

In region $\mathrm{C}$ firms form simultaneous cartels independent of the AA's prosecution strategies. The discounted, expected welfare loss with a simultaneous cartel and antitrust spillovers, denoted by $W_{2}^{S}$, is the welfare loss from a simultaneous cartel over 
the discounted, expected period in which no cartel is detected,

$$
W_{2}^{S}=\frac{L_{2}(\gamma)}{1-\delta(1-\rho)^{2}} .
$$

The AA invests in prosecution resources if and only if the welfare gains from an antitrust spillover outweigh the budgetary cost, i.e. $W_{2}-W_{2}^{S} \geq I$ or

$$
\frac{2 \rho(1-\rho)}{1-\delta(1-\rho)^{2}} \frac{\delta L_{1}(\gamma)}{1-\delta(1-\rho)} \geq I
$$

A large budget allows to investigate and prosecute in both markets if the AA detects one cartel while firms cartelize both markets. The first factor on the LHS is the expected, discounted time for such an antitrust spillover to occur. The second factor is the harm avoided by the spillover, i.e. the welfare loss from one cartel with an adjacent competitive market. Since this harm is strictly decreasing in $\gamma$, it is optimal for the AA to invest in prosecution if and only if the demand linkage parameter is sufficiently small.

Lemma 7 Consider parameter region $C$. There exists a $\gamma_{C}(I)$, with $\gamma_{C}^{\prime}<0$ and $\gamma_{C}(0)=\bar{\gamma}$, such that the $A A$ invests in prosecution resources if and only if $\gamma \leq \gamma_{C}(I)$.

In region $\mathrm{D}$ a cartel in one market is not sustainable if the adjacent market is competitive. If the AA detects and prosecutes one cartel, firms revert to competition in the adjacent market. This knock-on effect through cartel stability is a perfect substitute for antitrust spillovers. Hence, the AA has no incentive to invest in this parameter region.

In region E sequential cartels are not viable. If the AA's prosecution budget is low, firms form a simultaneous cartel that breaks down in both markets if at least one cartel is detected. If the AA has a high prosecution budget, cartels are deterred. Thus, the AA has an incentive to invest in prosecution if the welfare gain from deterring a simultaneous cartel outweighs the budgetary cost,

$$
\frac{L_{2}(\gamma)}{1-\delta(1-\rho)^{2}} \geq I
$$

Check that this constraint is always easier to satisfy than condition (8), i.e. the AA has more incentives to invest in region $\mathrm{E}$ than in region $\mathrm{B}$. To see this compare ex ante and ex post incentives. Without investment simultaneous cartels form in both regions. However, the expected welfare loss in region $\mathrm{B}$ is higher because in the case where only one cartel is detected, firms keep on colluding in the adjacent market in region $\mathrm{B}$ but not in $\mathrm{E}$. This provides stronger incentives to invest in region $\mathrm{B}$ by the 
magnitude of the welfare loss from a cartel in one market discounted by the cartel's expected start date. With investment, a cartel in region $\mathrm{E}$ is deterred whereas in region B firms form a sequential cartel. This provides stronger incentives to invest in region $\mathrm{E}$ by the magnitude of the welfare loss from a sequential cartel. Clearly, the stronger ex post incentives for region E outweigh the stronger ex ante incentives of region $\mathrm{B}$.

Finally, in region $\mathrm{F}$ cartels are deterred independent of the prosecution resources and the AA does not require to invest in additional resources. We summarize this discussion by characterizing the optimal prosecution strategy as a function of whether a simultaneous cartel can be deterred with and/or without the AA's investment.

Proposition 3 Assume I is sufficiently low.

(i) Suppose deterrence is weak such that simultaneous cartels form independent of prosecution resources. Then the AA invests in prosecution resources if and only if the markets are neither strong substitutes nor strong complements.

(ii) Suppose deterrence is intermediate such that simultaneous cartels form with a low but not with a high prosecution budget. Then the AA invests only if products are substitutes or weak complements.

(iii) Otherwise, the AA never invests in prosecution resources.

The AA's optimal prosecution strategy interacts with the level of ex ante cartel deterrence. Point (i) of Proposition 3 refers to parameter constellations in which cartel deterrence is low and firms form simultaneous cartels even if the AA has invested in prosecution resources, i.e. $F \leq F_{3}^{S}$. In such situations the optimal prosecution budget is non-linear in the demand linkage parameter $\gamma$. For strong complements (region A) firms form sequential cartels. For close substitutes (region D), the successful prosecution of a cartel in one market has a knock-on effect on the cartel in the adjacent market. In both cases a small prosecution budget is optimal. For intermediate values of $\gamma$ there exist two cases. In region $\mathrm{B}$ a high prosecution budget leads to sequential cartels which is desirable if the demand linkage parameter is sufficiently high, $\gamma \geq \gamma_{B}$. In region $\mathrm{C}$ firms form simultaneous cartels and increasing prosecution resources is beneficial if products are not too close substitutes, $\gamma \leq \gamma_{C}$. However, as shown in Lemma 6 and 7, as the investment cost $I$ goes to zero, $\gamma_{B}$ decreases and it is strictly negative while $\gamma_{C}$ increases and approaches $\bar{\gamma}$. Hence, there must exist intermediate values of the demand linkage parameter for which it is optimal to invest in prosecution resources. Next consider intermediate levels of ex ante cartel deterrence. Point (ii) of the proposition refers to values of $F$ such that simultaneous cartels are deterred with antitrust spillover $\left(F>F_{3}^{S}\right)$ but sustainable if the AA does not invest $(F \leq$ $\left.\min \left\{F_{2}, \max \left\{F_{1}, F_{3}\right\}\right\}\right)$. Three different cases can arise. For sufficiently low values of $\gamma$ 
sequential cartels are sustainable (regions A and B) and the AA invests like in the low deterrence case, that is for $\gamma \geq \gamma_{B}$. The difference to point ( $i$ ) in Proposition 3 arises if products are sufficiently close substitutes. In region E, sequential cartels are not sustainable and simultaneous cartels only form if the AA does not invest. Thus, the AA is able to deter collusion by investing in prosecution resources. Moreover, as pointed out above, the AA always has a stronger incentive to invest in region E compared to region B. So, if the investment cost $I$ is sufficiently small, then point (ii) follows and the AA invests if and only if the demand linkage parameter is sufficiently large. Finally, consider point (iii) and cases where deterrence is high such that simultaneous cartels never form. Then firms either form sequential cartels $\left(F_{2}<F \leq F_{1}\right)$ or there is no collusion at all. In both cases, the AA has no incentive to invest in prosecution.

\section{Conclusions}

In this paper, we analyze cartel dynamics of multi-market firms in the presence of antitrust enforcement. We show that demand relationships create important effects for cartel prosecution. Antitrust intervention in one market can reduce cartel stability and have a knock-on effect on cartel activities in the adjacent market. Cartel prosecution might also have a waterbed effect by increasing cartel stability and trigger collusion in previously competitive markets.

Our further analysis evaluates the implications of these effects for the optimal size of the cartel prosecution budget of an antitrust authority. With low ex ante cartel deterrence, investing in prosecution resources is optimal only if markets are neither strong complements nor strong substitutes. For intermediate levels of ex ante deterrence, a high prosecution budget is optimal only if products are substitutes or weak complements. 


\section{Appendix}

\section{Proof of Lemma 1}

From (3) follows that $F_{2}$ is implicitly defined by

$$
\rho F_{2}=\left[1-\frac{1-\delta(1-\rho)}{1-\delta(1-\rho)^{2}}\right] \frac{\Pi_{1}(\gamma)}{2}+\frac{[1-\delta(1-\rho)]\left[\delta(1-\rho)^{2}-1 / 2\right]}{1-\delta(1-\rho)^{2}} \Pi_{2}(\gamma) .
$$

If $\delta(1-\rho)^{2} \geq 1 / 2$, then the RHS is strictly positive and $F_{2}>0$. Next consider

$$
F_{1}-F_{2}=\frac{1-\delta(1-\rho)}{1-\delta(1-\rho)^{2}}\left[\delta(1-\rho)^{2}-1 / 2\right]\left[\Pi_{1}(\gamma)-\Pi_{2}(\gamma)\right]
$$

This implies that $F_{2} \leq F_{1}$ if the product of the squared brackets is positive. Point $(i)$ in the lemma refers to the case where both brackets are positive. Point (ii) holds if $\delta(1-\rho)^{2}<1 / 2$ and $\Pi_{1}(\gamma)<\Pi_{2}(\gamma)$. In this case it follows from (3) that the sustainability of a simultaneous cartel increases if $\Pi_{2}(\gamma)$ decreases. Denote as $\pi_{2}(\gamma)$ the maximum per market profit $\Pi_{2}(\gamma)$ that satisfies (3),

$$
\pi_{2}(\gamma)=\Pi_{1}(\gamma)+\frac{1-\delta(1-\rho)^{2}}{1 / 2-\delta(1-\rho)^{2}}\left[V_{1}^{C}-\Pi_{1}(\gamma)\right]
$$

Since the second term is positive for any $F \leq F_{1}$, firms can always sustain strictly positive partial collusion profits for $\max \left\{0, F_{2}\right\} \leq F \leq F_{1}$. From this the lemma follows. QED.

\section{Proof of Lemma 2}

There exist values such that condition (4) holds while (1) does not hold if and only if

$$
F_{3}-F_{1}=\frac{\left(\delta(1-\rho)^{2}-1 / 2\right)}{\rho} \Pi_{2}(\gamma)-\frac{(\delta(1-\rho)-1 / 2)}{\rho} \Pi_{1}(\gamma) \geq 0,
$$

or

$$
\frac{\Pi_{1}(\gamma)}{\Pi_{2}(\gamma)} \leq \frac{\delta(1-\rho)^{2}-1 / 2}{\delta(1-\rho)-1 / 2}
$$

The LHS is decreasing in $\gamma$ by assumption (A1). By assumption (A2) it takes value 1 at $\gamma=0$ and value 0 at $\bar{\gamma}$. If $\delta(1-\rho)^{2}<1 / 2$, then the RHS is negative and $F_{1}>F_{3}$ for all $\gamma$. If $\delta(1-\rho)^{2} \geq 1 / 2$, then the RHS is positive but less than 1 . It follows that there is a unique value $\gamma_{1}>0$ such that $F_{3} \geq F_{1}$ if and only if $\gamma \geq \gamma_{1}$. QED.

\section{Proof of Lemma 3}

From (5) follows that

$$
F_{4}=\frac{2 \Pi_{2}(\gamma)-\Pi_{1}(\gamma)}{2 \rho}+\frac{\rho \delta\left(\Pi_{2}(\gamma)-\Pi_{1}(\gamma)\right)}{(1-\delta)\left(1-\delta(1-\rho)^{2}\right)}
$$

Point (i) of the lemma follows from the discussion in the text. Consider $\gamma \leq 0$. Check that $\partial F_{4} / \partial \gamma \geq 0$ if and only if

$$
\Pi_{1}^{\prime}(\gamma) \leq\left[1-\frac{\delta \rho^{2}}{(1-\delta)\left(1-\delta(1-\rho)^{2}\right)+2 \delta \rho^{2}}\right] 2 \Pi_{2}^{\prime}(\gamma) .
$$


The fraction in the squared bracket is always positive but less than $1 / 2$ which implies that the squared bracket has a value between $1 / 2$ and 1 . Thus, by assumption (A1), this condition always holds. Next check that $F_{4} \geq 0$ if and only if

$$
\frac{\Pi_{1}(\gamma)}{\Pi_{2}(\gamma)} \leq 2\left[1-\frac{\delta \rho^{2}}{(1-\delta)\left(1-\delta(1-\rho)^{2}\right)+2 \delta \rho^{2}}\right]
$$

By assumptions (A1) and (A2) the LHS is strictly decreasing in $\gamma$ taking value 2 at $\gamma=\underline{\gamma}$ and value 1 at $\gamma=0$. The RHS takes values in [1,2]. It follows that there exist a unique $\gamma_{2}<0$ such that $F_{4} \geq 0$ if and only if $\gamma \geq \gamma_{2}$. To show that the last part of point (iii) in the lemma note that if $\delta(1-\rho)^{2} \geq 1 / 2$, then $F_{2} \leq F_{1}$ and the binding sustainability constraint is (3). Then we get that $F_{4} \leq F_{2}$ if and only if

$$
\frac{\Pi_{1}(\gamma)}{\Pi_{2}(\gamma)} \geq 1+\frac{2(1-\delta)\left(1-\delta(1-\rho)^{2}\right)}{1-\delta(1-\rho)+\delta \rho}
$$

The LHS is decreasing in $\gamma$, takes value 2 at $\gamma=\underline{\gamma}$ and value 1 at $\gamma=0$. The RHS is larger than 1 and decreasing in $\rho$. Its maximum at $\rho=0$ is $3+2(1-\delta)$ which is less than 2 for any $\delta \geq 1 / 2$. It follows that there exists a unique value $\gamma_{3}^{\prime}<0$ such that $F_{4} \leq F_{2}$ if and only if $\gamma \leq \gamma_{3}^{\prime}$. If $\delta(1-\rho)^{2}<1 / 2$, then $F_{1} \leq F_{2}$ and the binding sustainability constraint is $(1)$. $F_{1}$ is decreasing in $\gamma$ and equal to $F_{2}$ at $\gamma=0 . F_{4}$ is increasing in $\gamma$ and equal to $F_{2}$ at $\gamma=\gamma_{3}^{\prime}$. Hence, there exists a value $\gamma_{3}^{\prime \prime}<\gamma_{3}^{\prime}<0$ such that $F_{4} \leq F_{1}$ if and only if $\gamma \leq \gamma_{3}^{\prime \prime}$. QED.

\section{Proofs of Lemma 4 and 5}

For Lemma 4 verify that $F_{3}^{S} \geq F_{1}$ iff

$$
\frac{\Pi_{1}(\gamma)}{\Pi_{2}(\gamma)} \leq \frac{\delta(1-\rho)^{2}-1 / 2}{(\delta(1-\rho)-1 / 2)(2-\rho)}
$$

The RHS is strictly smaller than the RHS in A-1. Hence there exists a $\gamma_{1}^{S}>\gamma_{1}$ such that $F_{3}^{S} \geq F_{1}$ if and only if $\gamma \geq \gamma_{1}^{S}$. The lemma follows.

For Lemma 5 differentiating the LHS of $(7)$ with respect to $F$ yields

$$
-\frac{(1-\delta)[3(1-\rho)(1-\delta(1-\rho))+\rho]}{\left[1-\delta(1-\rho)^{2}\right][1-\delta(1-\rho)]^{2}}<0
$$

Thus, (7) holds if $F$ is sufficiently low or, vice versa, sequential cartels are optimal if $F \geq F_{4}^{S}$. Solving (7) for $F$ gives

$$
F_{4}^{S}=\frac{[1-\delta(1-\rho)]^{2} \Pi_{2}(\gamma)-\left[1-\delta(1-\rho)^{2}\right][1-\delta(1-2 \rho)] \Pi_{1}(\gamma) / 2}{(1-\delta) \rho[3(1-\rho)(1-\delta(1-\rho))+\rho]} .
$$

Next check that $F_{4}>F_{4}^{S}$ if and only if

$$
\frac{\Pi_{1}(\gamma)}{\Pi_{2}(\gamma)}<\frac{2[1-\delta(1-\rho)]}{1-\delta\left(1-\rho^{2}\right)}
$$


which holds since by assumptions (A1) and (A2) the LHS takes values between 0 and 2 while the RHS is greater than 2. Further $F_{4}^{S}$ is increasing in $\gamma$ if and only if

$$
\Pi_{1}^{\prime}(\gamma)<\left[1-\frac{\delta \rho\left(2-\rho-2 \delta(1-\rho)^{2}\right)}{\left(1-\delta(1-\rho)^{2}\right)(1-\delta(1-2 \rho))}\right] 2 \Pi_{2}^{\prime}(\gamma)
$$

The numerator of the fraction on the RHS is positive for $\delta(1-\rho) \geq 1 / 2$. Hence, the fraction is positive, the squared bracket is less than 1 and by assumption (A1) this condition is satisfied. Existence and uniqueness of $\gamma_{2}^{S}$ and $\gamma_{3}^{S}$, with $\gamma_{2}^{S} \leq \gamma_{3}^{S}$, follow from $F_{4}<F_{4}^{S}$ and the fact that $F_{4}^{S}$ is increasing while $F_{1}$ is decreasing in $\gamma$. Finally, to show that $\gamma_{3}^{S}<\gamma_{1}^{S}$ note that along $F_{1}$ it holds that $V_{1}^{C}=\Pi_{1}$ and $V_{11}=[1-\delta(1-\rho)+\delta \rho] \Pi_{1} /[1-\delta(1-\rho)]$. Along $F_{3}^{S}$ it holds that $V_{2}^{S}=2 \Pi_{2}$. Thus, at $F_{1}\left(\gamma_{1}^{S}\right)=F_{3}^{S}\left(\gamma_{1}^{S}\right)$ a simultaneous cartel is optimal if

$$
\frac{\Pi_{1}(\gamma)}{\Pi_{2}(\gamma)}<1+\frac{1-\delta}{1-\delta(1-\rho)+\delta \rho}
$$

which always holds since $\gamma_{1}^{S}<0, \Pi_{1}\left(\gamma_{1}^{S}\right) / \Pi_{2}\left(\gamma_{1}^{S}\right)<1$ and the RHS is strictly larger than 1 . From this and $\partial F_{4}^{S} / \partial \gamma>0$ and Lemma 4 follows $\gamma_{3}^{S}<\gamma_{1}^{S}$. QED.

\section{Proofs of Lemma 6}

Rewrite $(8)$ as

$$
-\frac{\delta \rho^{2} L_{1}(\gamma)}{(1-\delta(1-\rho))^{2}\left(1-\delta(1-\rho)^{2}\right)}+\frac{L_{2}(\gamma)-L_{1}(\gamma)}{1-\delta(1-\rho)^{2}} \geq I
$$

By Assumption (A4), the first term on the LHS is strictly and the second weakly increasing in $\gamma$. It follows that the welfare gain from a sequential cartel strictly increases. At $\gamma=\underline{\gamma}$ it holds that $L_{1}(\underline{\gamma})=L_{2}(\underline{\gamma})$. Hence the second term in $\mathrm{A}-2$ is zero and the LHS is negative. The rest of the lemma follows from the positive slope of the LHS, its negative value at $\gamma=\underline{\gamma}$ and its non-negative value at $\gamma=0$ (see text). QED.

\section{References}

Abreu, D., "On the Theory of Infinitely Repeated Games with Discounting " Econometrica (56), 1988, pp. 383-396.

Aubert, C., Rey, P., And Kovacic, W. E., "The Impact of Leniency and WhistleBlowing Programs on Cartels" International Journal of Industrial Organization (24), 2006, pp. 1241-1266.

Bryant, P. And Eckard, E. Woodrow, "The Probability of Getting Caught", The Review of Economics and Statistics (73), August 1991, pp. 531-536.

Bernheim, D. And Whinston, M.D., "Multimarket Contact and Collusive Behavior," RAND Journal of Economics (21), Spring 1990, pp. 1-26. 
Choi, J. P. and Gerlach, H., "International Antitrust Enforcement and Multi-market Contact", CESifo Working Paper No. 2599, available at http://ssrn.com/abstract=1368668, 2009.

Connor, J. M., "Global Price Fixing", Springer Berlin, Heidelberg, 2nd updated and revised edition, 2007.

EC Commission Decision of 21 November 2001 relating to a proceeding pursuant to Article 81 of the EC Treaty and Article 53 of the EEA Agreement (COMP/E-1/37.512-Vitamins). Brussels. January 10, 2003.

Harrington, J. E., "Cartel Pricing Dynamics in the Presence of an Antitrust Authority", RAND Journal of Economics (35), Winter 2004, 651-673.

Harrington, J. E., "Optimal Cartel Pricing in the Presence of an Antitrust Authority", International Economic Review (46), February 2005, 145-169.

Harrington, J. E., "Optimal Corporate Leniency Programs", Journal of Industrial Economics (56), 2008, pp. 215-246.

Kovacic, W., Marshall, R.C., Marx L.M. and Raiff, M.E., "Post-Plea Pricing: Lessons for Competition Policy from the Vitamins Cartel", in: The Political Economy of Antitrust, V. Ghosal and J. Stenneck (editors). Elsevier, Amsterdam: North Holland, 2007.

Motta, M. And Polo, M., "Leniency Programs and Cartel Prosecution" International Journal of Industrial Organization (21), 2003, pp. 347-379.

Nocke, V. And White, L., "Do Vertical Mergers Facilitate Upstream Collusion?" American Economic Review (97), September 2007, pp. 1321-1339.

Roux, C. and von Ungern-Sternberg, T., "Leniency Programs in a Multimarket Setting: Amnesty Plus and Penalty Plus," CESIfo Working Paper No. 1995, May 2007.

Singh, N. And Vives, X., "Price and Quantity Competition in a Differentiated Duopoly", RAND Journal of Economics (15), Winter 1984, 546-554.

Spagnolo, G., "On Interdependent Supergames: Multimarket Contact, Concavity, and Collusion", Journal of Economic Theory (89), 1999, pp. 127-139. 


\section{CESifo Working Paper Series}

for full list see www.cesifo-group.org/wp

(address: Poschingerstr. 5, 81679 Munich, Germany, office@cesifo.de)

2569 Bart Cockx and Matteo Picchio, Are Short-Lived Jobs Stepping Stones to Long-Lasting Jobs?, March 2009

2570 David Card, Jochen Kluve and Andrea Weber, Active Labor Market Policy Evaluations: A Meta-analysis, March 2009

2571 Frederick van der Ploeg and Anthony J. Venables, Harnessing Windfall Revenues: Optimal Policies for Resource-Rich Developing Economies, March 2009

2572 Ondřej Schneider, Reforming Pensions in Europe: Economic Fundamentals and Political Factors, March 2009

2573 Jo Thori Lind, Karl Ove Moene and Fredrik Willumsen, Opium for the Masses? Conflict-Induced Narcotics Production in Afghanistan, March 2009

2574 Silvia Marchesi, Laura Sabani and Axel Dreher, Agency and Communication in IMF Conditional Lending: Theory and Empirical Evidence, March 2009

2575 Carlo Altavilla and Matteo Ciccarelli, The Effects of Monetary Policy on Unemployment Dynamics under Model Uncertainty - Evidence from the US and the Euro Area, March 2009

2576 Falko Fecht, Kjell G. Nyborg and Jörg Rocholl, The Price of Liquidity: Bank Characteristics and Market Conditions, March 2009

2577 Giorgio Bellettini and Filippo Taddei, Real Estate Prices and the Importance of Bequest Taxation, March 2009

2578 Annette Bergemann and Regina T. Riphahn, Female Labor Supply and Parental Leave Benefits - The Causal Effect of Paying Higher Transfers for a Shorter Period of Time, March 2009

2579 Thomas Eichner and Rüdiger Pethig, EU-Type Carbon Emissions Trade and the Distributional Impact of Overlapping Emissions Taxes, March 2009

2580 Antonios Antypas, Guglielmo Maria Caporale, Nikolaos Kourogenis and Nikitas Pittis, Selectivity, Market Timing and the Morningstar Star-Rating System, March 2009

2581 António Afonso and Christophe Rault, Bootstrap Panel Granger-Causality between Government Budget and External Deficits for the EU, March 2009

2582 Bernd Süssmuth, Malte Heyne and Wolfgang Maennig, Induced Civic Pride and Integration, March 2009 
2583 Martin Peitz and Markus Reisinger, Indirect Taxation in Vertical Oligopoly, March 2009

2584 Petra M. Geraats, Trends in Monetary Policy Transparency, March 2009

2585 Johannes Abeler, Armin Falk, Lorenz Götte and David Huffman, Reference Points and Effort Provision, March 2009

2586 Wolfram F. Richter, Taxing Education in Ramsey’s Tradition, March 2009

2587 Yin-Wong Cheung, Menzie D. Chinn and Eiji Fujii, China's Current Account and Exchange Rate, March 2009

2588 Alexander Haupt and Silke Uebelmesser, Voting on Labour-Market Integration and Education Policy when Citizens Differ in Mobility and Ability, March 2009

2589 Hans Jarle Kind, Marko Koethenbuerger and Guttorm Schjelderup, Should UtilityReducing Media Advertising be Taxed?, March 2009

2590 Alessandro Cigno, How to Avoid a Pension Crisis: A Question of Intelligent System Design, March 2009

2591 Helmut Lütkepohl and Fang Xu, The Role of the Log Transformation in Forecasting Economic Variables, March 2009

2592 Rainald Borck, Hyun-Ju Koh and Michael Pflüger, Inefficient Lock-in and Subsidy Competition, March 2009

2593 Paolo M. Panteghini, On the Equivalence between Labor and Consumption Taxation, March 2009

2594 Bruno S. Frey, Economists in the PITS?, March 2009

2595 Natalie Chen and Dennis Novy, International Trade Integration: A Disaggregated Approach, March 2009

2596 Frédérique Bec and Christian Gollier, Term Structure and Cyclicity of Value-at-Risk: Consequences for the Solvency Capital Requirement, March 2009

2597 Carsten Eckel, International Trade and Retailing, March 2009

2598 Gianni De Nicolò and Iryna Ivaschenko, Global Liquidity, Risk Premiums and Growth Opportunities, March 2009

2599 Jay Pil Choi and Heiko Gerlach, International Antitrust Enforcement and Multi-Market Contact, March 2009

2600 Massimo Bordignon and Guido Tabellini, Moderating Political Extremism: Single Round vs Runoff Elections under Plurality Rule, April 2009 
2601 Ana B. Ania and Andreas Wagener, The Open Method of Coordination (OMC) as an Evolutionary Learning Process, April 2009

2602 Simon Gächter, Daniele Nosenzo, Elke Renner and Martin Sefton, Sequential versus Simultaneous Contributions to Public Goods: Experimental Evidence, April 2009

2603 Philippe Jehiel and Andrew Lilico, Smoking Today and Stopping Tomorrow: A Limited Foresight Perspective, April 2009

2604 Andreas Knabe, Steffen Rätzel, Ronnie Schöb and Joachim Weimann, Dissatisfied with Life, but Having a Good Day: Time-Use and Well-Being of the Unemployed, April 2009

2605 David Bartolini and Raffaella Santolini, Fiscal Rules and the Opportunistic Behaviour of the Incumbent Politician: Evidence from Italian Municipalities, April 2009

2606 Erkki Koskela and Jan König, Can Profit Sharing Lower Flexible Outsourcing? A Note, April 2009

2607 Michel Beine, Frédéric Docquier and Çağlar Özden, Diasporas, April 2009

2608 Gerd Ronning and Hans Schneeweiss, Panel Regression with Random Noise, April 2009

2609 Adam S. Booij, Bernard M.S. van Praag and Gijs van de Kuilen, A Parametric Analysis of Prospect Theory's Functionals for the General Population, April 2009

2610 Jeffrey R. Brown, Julia Lynn Coronado and Don Fullerton, Is Social Security Part of the Social Safety Net?, April 2009

2611 Ali Bayar and Bram Smeets, Economic, Political and Institutional Determinants of Budget Deficits in the European Union, April 2009

2612 Balázs Égert, The Impact of Monetary and Commodity Fundamentals, Macro News and Central Bank Communication on the Exchange Rate: Evidence from South Africa, April 2009

2613 Michael Melvin, Christian Saborowski, Michael Sager and Mark P. Taylor, Bank of England Interest Rate Announcements and the Foreign Exchange Market, April 2009

2614 Marie-Louise Leroux, Pierre Pestieau and Gregory Ponthiere, Should we Subsidize Longevity?, April 2009

2615 Ronald MacDonald, Lukas Menkhoff and Rafael R. Rebitzky, Exchange Rate Forecasters' Performance: Evidence of Skill?, April 2009

2616 Frederick van der Ploeg and Steven Poelhekke, The Volatility Curse: Revisiting the Paradox of Plenty, April 2009 
2617 Axel Dreher, Peter Nunnenkamp, Hannes Öhler and Johannes Weisser, Acting Autonomously or Mimicking the State and Peers? A Panel Tobit Analysis of Financial Dependence and Aid Allocation by Swiss NGOs, April 2009

2618 Guglielmo Maria Caporale, Roman Matousek and Chris Stewart, Rating Assignments: Lessons from International Banks, April 2009

2619 Paul Belleflamme and Martin Peitz, Asymmetric Information and Overinvestment in Quality, April 2009

2620 Thomas Dohmen, Armin Falk, David Huffman and Uwe Sunde, Are Risk Aversion and Impatience Related to Cognitive Ability?, April 2009

2621 Yin-Wong Cheung and Xingwang Qian, The Empirics of China's Outward Direct Investment, April 2009

2622 Frédérique Bec and Christian Gollier, Assets Returns Volatility and Investment Horizon: The French Case, April 2009

2623 Ronnie Schöb and Marcel Thum, Asymmetric Information Renders Minimum Wages Less Harmful, April 2009

2624 Martin Ruf and Alfons J. Weichenrieder, The Taxation of Passive Foreign Investment Lessons from German Experience, April 2009

2625 Yao Li, Borders and Distance in Knowledge Spillovers: Dying over Time or Dying with Age? - Evidence from Patent Citations, April 2009

2626 Jim Malley and Ulrich Woitek, Technology Shocks and Aggregate Fluctuations in an Estimated Hybrid RBC Model, April 2009

2627 Jin Cao and Gerhard Illing, Endogenous Systemic Liquidity Risk, April 2009

2628 Thiess Buettner and Bjoern Kauder, Revenue Forecasting Practices: Differences across Countries and Consequences for Forecasting Performance, April 2009

2629 Håkan Selin, The Rise in Female Employment and the Role of Tax Incentives - An Empirical Analysis of the Swedish Individual Tax Reform of 1971, April 2009

2630 Nick Johnstone and Ivan Hascic, Environmental Policy Design and the Fragmentation of International Markets for Innovation, April 2009

2631 Spiros Bougheas, Richard Kneller and Raymond Riezman, Optimal Education Policies and Comparative Advantage, April 2009

2632 Jay Pil Choi and Heiko Gerlach, Multi-Market Collusion with Demand Linkages and Antitrust Enforcement, April 2009 